\title{
CIDADANIA NAS POLÍTICAS PÚBLICAS DE CONSUMO NO BRASIL
}

\section{Fernando Büscher von Teschenhausen Eberlin}

Graduação em Direito pela Universidade Presbiteriana Mackenzie (2002). Especialização em Direito da Responsabilidade Civil pela Fundação Getúlio Vargas (2006). Mestrado em Direito Político e Econômico pela Universidade Presbiteriana Mackenzie (2010) e MBA em Ciências do Consumo Aplicadas pela Escola Superior de Propaganda e Marketing (2015). Doutorando em Direito Político e Econômico pela Universidade Presbiteriana Mackenzie. Professor do Programa de Pós-Graduação Lato Sensu de Direito SP (Fundação Getúlio Vargas - SP) e advogado em São Paulo. Orcid: <http://orcid.org/0000-0001-50035381>.fernando@eberlin.adv.br

\section{Resumo:}

0 objetivo do presente artigo é estudar as possíveis acepções de cidadania ligada ao consumo, assim como a presença desta ideia nas políticas públicas de consumo do Sistema Nacional de Defesa do Consumidor (SNDC), em especial no âmbito do Plano Nacional de Consumo e Cidadania (Plandec). A metodologia utilizada consistiu em revisitar a bibliografia sobre as possíveis acepções de cidadania ligada ao consumo; estudar a estrutura do SNDC, bem como as suas principais características e as limitações do sistema para a articulação de políticas públicas e analisar o marco legal e os efeitos concretos do Plandec, sobretudo no que se relaciona à concretização da cidadania. A partir desta metodologia, verificou-se que o marco legal do SNDC prioriza procedimentos de fiscalização, aplicação de penalidades e processos administrativos em detrimento de mecanismos de articulação entre os seus órgãos; e que a Secretaria Nacional do Consumidor (Senacon), responsável pela coordenação do SNDC, vem concentrando suas ações para aumentar a integração entre os órgãos do SNDC (em especial com os Procons). Com base em tais constatações, concluiu-se que a concretização da cidadania nas políticas públicas de consumo demanda uma efetiva integração ao SNDC das entidades civis de defesa do consumidor, assim como a elaboração de políticas que envolvam a participação de fornecedores, favorecendo a harmonização das relações de consumo.

\section{Palavras-chave:}

Direito do consumidor. Cidadania. Sistema Nacional de Defesa do Consumidor. Políticas públicas de consumo.

\section{CITIZENSHIP IN THE CONSUMPTION PUBLIC POLICIES IN BRAZIL}

\section{Abstract:}

The purpose of this paper is to study the possible meanings of citizenship linked to consumption, as well as the presence of this idea in the Consumption Public Policies proposed by the Brazilian Consumer Defense Administrative System (SNDC), especially in the scope 
of the National Plan of Consumption and Citizenship (Plandec). The methodology used consists of revisiting the bibliography regarding the possible meanings of citizenship related to consumption; studying the structure of the SNDC, as well as its main characteristics and the limitations of the system for articulating Public Policies; and analyzing the legal framework and the concrete effects of Plandec, especially with regard to the implementation of citizenship. Based on that, it was verified that SNDC's legal framework focuses on the inspection procedures, on the application of administrative penalties and on the administrative processes instead of focusing on the mechanisms of articulation between its organs; and that the National Consumer Secretariat (Senacon), responsible for the coordination of the SNDC, has been concentrating its actions to increase the integration between SNDC's bodies (mainly the Procons). The conclusion obtained is in the sense that the concretization of citizenship in Consumption Public Policies demands an effective integration into the SNDC of private consumer organizations, as well as the implementation of Policies involving the participation of Suppliers, in order to enhance the harmonization of consumer relations.

\section{Keywords:}

Consumer law. Citizenship. Brazilian Consumer Defense Administrative System. Consumption public policies.

Recebido em: 10/7/2017

Aceito em: 4/6/2018

\section{Sumário:}

1 Introdução. 2 Cidadania e Consumo. 30 SNDC e a Articulação dos Órgãos de Defesa do Consumidor. 4 Políticas Públicas de Consumo no Brasil. 5 Conclusão. 6 Referências. 


\section{INTRODUÇÃO}

O estudo do consumo e de suas consequências sobre os aspectos econômicos e sociais vem ganhando importância nos últimos tempos. Do lado antropológico, o consumo representa atribuição de valor simbólico a bens e serviços; ${ }^{1}$ no aspecto sociológico, o consumo é uma maneira de integração social; já no plano jurídico, a proteção ao consumidor tem relevância constitucional e pode constituir um dos aspectos da dimensão contemporânea de cidadania.

Não obstante isso, ainda existe uma dificuldade de articulação entre os órgãos que compóem o Sistema Nacional de Defesa do Consumidor (SNDC), instituído em 1997, para que possam convergir em ações que efetivem a dimensão cidadã do consumo. O Plano Nacional de Consumo e Cidadania (Plandec), criado em 2013, demonstrou a intenção do Estado de inserir a defesa do consumidor e a dimensão cidadã deste direito na agenda do Estado.

Neste contexto, o objetivo deste artigo é conhecer em que medida o consumo pode ser entendido como uma expressão da cidadania, bem como se as políticas públicas existentes são capazes de concretizar o viés "cidadão" do consumo. Para tanto, na Seção 2 será trabalhado o conceito de cidadania ligada ao consumo. $\mathrm{Na}$ Seção 3, será analisado o SNDC e sua formatação jurídica. Por fim, na Seção 4 será feita uma análise do Plandec e das políticas públicas dele derivadas, a fim de entender o "estado da arte" do Estado Brasileiro em relação ao tema proposto.

\section{CIDADANIA E CONSUMO}

A respeito da cidadania, Smanio demonstra como as dimensóes deste conceito evoluíram. Num primeiro momento, tem-se a ideia do cidadão como nacional de um Estado. Depois, há o entendimento do cidadão como indivíduo sujeito de direitos. Posteriormente, fala-se na dimensão que envolve a participação

1 Pina e Arribas lembram da perspectiva antropológica, que "concebe o consumo, no mundo capitalista contemporâneo, como um corpo de práticas, imagens e representaçóes, em volta às quais as pessoas confrontam o Estado e o mercado nos processos cotidianos de definição deles mesmos e da construção de projetos morais e de valor" (PINA; ARRIBAS, 2006, p. 81). 
política. Em seguida, a cidadania ganha uma conotação liberal até que, finalmente, alcança a ideia de inclusão social e multiculturalidade (SMANIO, 2009). Ao pensar nas relaçôes de consumo e confrontá-las com as dimensóes da cidadania, algumas ideias podem surgir.

A primeira dessas ideias é pensar no consumidor como titular do direito à adequada e eficaz prestação dos serviços públicos (Código de Defesa do Consumidor - $\mathrm{CDC}-$, artigo $\left.6^{\circ}, \mathrm{X}\right)$. Esse direito é respaldado pelo princípio da racionalização e melhoria dos serviços públicos, previsto no artigo $4^{\circ}$, VII do CDC. Nesta acepção, o consumidor do Estado faz jus a um ordenamento protetivo que lhe assegure prestaçóes adequadas nas situaçóes em que a legislação consumerista seja aplicável. ${ }^{2}$

Uma segunda acepção do consumidor cidadão seria a dimensão individual do conceito. Nessa situação, pode-se vislumbrar o consumidor como sujeito de direitos, que tem resguardado o acesso a bens de consumo adequados, seguros e capazes de proporcionar melhoria na sua qualidade de vida. No aspecto individual, talvez o mais desenvolvido no Direito brasileiro até o momento, o consumidor possui uma série de proteções contra produtos e serviços defeituosos, cláusulas abusivas, publicidade enganosa, práticas comerciais desleais, além de garantias processuais como a inversão do ônus da prova e a possibilidade de defesa coletiva dos direitos difusos, coletivos e individuais homogêneos.

2 Atualmente, a maior parte da doutrina considera que o Estado é fornecedor de serviços perante o CDC sempre e quando ofereça, direta ou indiretamente (por meio de concessão), um serviço público específico e divisível, mediante remuneração ligada especificamente ao serviço prestado (como uma tarifa ou taxa). Serviços remunerados indiretamente e que náo possam ser mensurados individualmente (normalmente serviços remunerados mediante impostos) estariam fora do âmbito de aplicaçáo do CDC. Assim, o pagamento de tarifa para transporte público ou para uma concessionária mantenedora de rodovias atrai a aplicaçáo do CDC, o que não ocorre com serviços que representam uma função estatal própria, tais como saúde e educação públicas. Sobre o tema, verificar o texto de Pellegrini que explica as posiçóes doutrinárias a respeito da aplicação do CDC ao Estado e corrobora a posição adotada neste artigo (PELLEGRINI, 2016). 
Ainda nessa dimensão individual, o consumo pode ser relacionado à ideia de cidadania inclusiva, explicada por Smanio como aquela que "precisa ter uma dimensão de inclusão social" (SMANIO, 2009, p. 17). Nessa linha, Taschner sustenta que o consumo pode significar a inclusão das pessoas em determinadas comunidades, tendo o efeito de integrar e proporcionar o acesso à cidadania (2010, p. 49). ${ }^{3}$

O aspecto da cidadania envolvendo o consumo também é bem ilustrado por Pina e Arribas, que sustentam que a cidadania também se manifesta no consumo consciente, em que as pessoas entendem que uma opçáo de compra representa um "voto por uma forma de produção, de comercialização e por um estilo de consumo" (PINA; ARRIBAS, 2006, p. 92). ${ }^{4}$

Interessante é entender como essa ideia de cidadania consumerista inclusiva se desenvolveu no Brasil. Para tanto, deve-se ter em mente que a inclusão social, de um modo geral, pode ser resultado de pressóes decorrentes de movimentos sociais ou da iniciativa do Estado. No Brasil, no que diz respeito ao consumo, não há registro de movimentos sociais de consumidores pleiteando mudanças em métodos produtivos ou de prestação de serviços. A evolução das relaçôes de consumo em nosso país demonstra que os movimentos de proteção aos consumidores emanaram do Estado e não da sociedade civil.

3 Para a autora, o consumo "é um mecanismo de integração social, no sentido de que a posse de determinados produtos e o acesso a determinados serviços tornaram-se instrumentos para a construçáo e reforço de identidades sociais e, em decorrência, para o reconhecimento de um indivíduo como cidadão. [...] a mesma cultura de consumo que leva ao consumismo e pode ser vista como empecilho para o exercício de práticas políticas conscientes, também gera práticas de consumo que, em dimensão simbólica, adquirem contornos de integraçáo social e acesso à cidadania, no sentido de reconhecimento de indivíduos ou grupos como membros legítimos de uma comunidade" (TASCHNER, 2010, p. 50).

4 "Mas o saber, como consciência, não se esgota em saber como escolher; implica também saber que as decisóes do consumo não são neutras: com cada produto que se compra e se desfruta, com cada serviço que se usa, se está dando um voto por uma forma de produção, de comercialização e por um estilo de consumo. Nesse sentido, ser consciente é parte da cidadania. É saber que se faz parte dum coletivo e que as decisōes podem conduzir a sociedade por uma via ou outra. É saber que se faz parte das soluçóes de problemas das sociedades ricas, pelos excessos, e das pobres, pela falta; participa-se das soluçôes dos problemas do ser humano, das relaçôes de trabalho e da exploração do meio ambiente" (PINA; ARRIBAS, 2006, p. 92). 
$\mathrm{Na}$ linha do exposto anteriormente, Volpi lembra que "a defesa do consumidor no Brasil foi fruto de iniciativa de um governo estadual”, notadamente o governo de São Paulo, que criou em 1976 o Sistema Estadual de Proteção ao Consumidor, que foi o primeiro Procon do Brasil (VOLPI, 2007, p. 100). O autor também recorda que uma das primeiras mobilizaçóes de consumidores ocorreu apenas no meio da década de 80, com a mudança de moeda no Plano Cruzado, quando o governo, por intermédio da Superintendência Nacional do Abastecimento (Sunab), convocou os consumidores para ajudar a fiscalizar os reajustes de preços (2007, p. 102).

Por fim, uma terceira acepção de cidadania ligada ao consumo estaria revelada na dimensão coletiva do conceito. Por dimensão coletiva pode-se entender toda e qualquer atitude individual, coletiva ou mesmo uma política pública que seja capaz de revelar aspectos transindividuais relevantes para a sociedade de consumo.

Um exemplo disso é a ideia de sustentabilidade, que muitas vezes implica a prática de atitudes em detrimento de interesses individuais. Outro exemplo seriam os modelos de negócio que se desenvolvem com pensamentos de consumo menos individuais, como é o caso da economia compartilhada (sistema que privilegia o compartilhamento de serviços e o acesso a produtos em detrimento da propriedade). ${ }^{5}$ Também estaria incluída na dimensão coletiva da cidadania consumerista a preocupação com situaçóes que tenham reflexos sociais ao colocarem o consumidor em posição de extrema vulnerabilidade, como é o caso do superendividamento.

Ainda no que respeita ao entendimento do Direito do Consumidor sob o aspecto coletivo e conjuntural, Prothero et al. propóem que as políticas públicas considerem não apenas os direitos, mas também os deveres dos

5 Maurer et al. frisam que os sistemas de economia compartilhada "fornecem benefícios ambientais significativos ao aumentar a eficiência de uso, reduzir o desperdício, ao incentivar o desenvolvimento de produtos melhores e ao absorver o excedente criado pelo excesso de produção e consumo (...) Tendo em vista que os bens são de propriedade conjunta, há uma provável redução do número total de bens adquiridos pelos consumidores individualmente" (MAURER et al., 2015, p. 71). 
consumidores-cidadãos (2011, p. 33). Esses deveres são uma decorrência do direito de escolha do consumidor individual, que terá impactos sobre a vida das outras pessoas. ${ }^{6}$

De fato, a dimensão coletiva da "cidadania consumerista" também envolve uma participação ativa do consumidor, inclusive como ator político. Verbicaro (2017) lembra que o CDC traz instrumentos em sua Política Nacional das Relaçôes de Consumo para que o consumidor exerça uma cidadania participativa, a qual, por seu turno, depende da crença do cidadão de que pode transformar a realidade social, política e econômica do país.

O consumo, como se vê, pode ser uma forma de expressão da dimensão contemporânea da cidadania. Em complemento a esta ideia, Volpi define a cidadania como "condição primordial para o estabelecimento das bases das relaçóes de consumo" (2007, p. 69). Ou seja, cidadania e consumo mostram-se intimamente ligados.

De um ponto de vista constitucional, a proteção ao consumidor faz-se presente em diversos momentos na Carta Magna de 1988. A CF trata do tema quando menciona os Direitos e Deveres Individuais e Coletivos no artigo 5º (estabelecendo no inciso XXXII que o Estado deve promover a defesa do consumidor); quando estabelece a competência concorrente dos entes federativos para legislar sobre a responsabilidade por dano ao consumidor (artigo 24, VIII); ao determinar que os consumidores sejam esclarecidos sobre os impostos incidentes sobre mercadorias e serviços (artigo 150, parágrafo $5^{\circ}$ ); e ao definir a defesa do consumidor como princípio da ordem econômica (artigo 170, V).

\footnotetext{
6 "Notably, the consumer-citizen notion puts on the agenda the need for policy makers to develop and promote consumer education that includes not only the rights but also the responsibilities of the consumer-citizen" (PROTHERO et al., 2011, p. 35).

7 "O sucesso da Política Nacional das Relações de Consumo, das Associações Representativas de Defesa do Consumidor, da Convenção Coletiva de Consumo prevista no artigo 107 do CDC (...) e dos demais espaços de autoridade política compartilhada criados a partir do microssistema consumerista (audiências públicas, conselhos, conferências, etc.) depende, em grande parte, da crença do consumidor de que pode transformar a realidade social, política e econômica do país. Caso tais vias de atuaçáo cidadã não propiciem mudanças concretas ou se náo forem percebidas como canais democráticos eficientes, haverá a perda de credibilidade das mesmas e o consequente desinteresse do consumidor em continuar investindo nessa linha de atuaçáo" (VERBICARO, 2017).
} 
A importância constitucional atribuída ao tema, em conjunto com os princípios norteadores das relaçóes de consumo previstos no artigo $4^{\circ}$ do CDC, ${ }^{8}$ demonstra o reconhecimento da importância do consumidor como um ente econômico, titular de direitos e de um dever de proteção que deve partir do Estado. Para cumprir esse dever o Estado brasileiro criou o Sistema Nacional de Defesa do Consumidor, que é objeto da próxima seção.

\section{O SNDC E A ARTICULAÇÃO DOS ÓRGÃOS DE DEFESA DO CONSUMIDOR}

Um sistema estatal devidamente organizado é essencial para a instituição de políticas que possam concretizar os direitos e objetivos previstos na Constituição Federal e nas normas específicas de cada sistema. As políticas públicas (que serão estudadas na próxima seção) podem ser definidas como o "conjunto de medidas articuladas (coordenadas), cujo escopo é dar impulso, isto é, movimentar a máquina do governo, no sentido de realizar algum objetivo de ordem pública, ou, na ótica dos juristas, concretizar um direito" (BUCCI, 2006, p. 14).

8 "Art. 40 A Política Nacional das Relaçóes de Consumo tem por objetivo o atendimento das necessidades dos consumidores, o respeito à sua dignidade, saúde e segurança, a proteçáo de seus interesses econômicos, a melhoria da sua qualidade de vida, bem como a transparência e harmonia das relaçôes de consumo, atendidos os seguintes princípios: I - reconhecimento da vulnerabilidade do consumidor no mercado de consumo; II - açăo governamental no sentido de proteger efetivamente o consumidor: a) por iniciativa direta; b) por incentivos à criaçáo e desenvolvimento de associaçóes representativas; c) pela presença do Estado no mercado de consumo; d) pela garantia dos produtos e serviços com padrôes adequados de qualidade, segurança, durabilidade e desempenho; III - harmonização dos interesses dos participantes das relaçôes de consumo e compatibilização da proteção do consumidor com a necessidade de desenvolvimento econômico e tecnológico, de modo a viabilizar os princípios nos quais se funda a ordem econômica (art. 170, da Constituição Federal), sempre com base na boa-fé e equilíbrio nas relaçóes entre consumidores e fornecedores; IV - educação e informação de fornecedores e consumidores, quanto aos seus direitos e deveres, com vistas à melhoria do mercado de consumo; $\mathrm{V}$ - incentivo à criaçáo pelos fornecedores de meios eficientes de controle de qualidade e segurança de produtos e serviços, assim como de mecanismos alternativos de solução de conflitos de consumo; VI - coibição e repressão eficientes de todos os abusos praticados no mercado de consumo, inclusive a concorrência desleal e utilização indevida de inventos e criaçôes industriais das marcas e nomes comerciais e signos distintivos, que possam causar prejuízos aos consumidores; VII - racionalizaçáo e melhoria dos serviços públicos; VIII - estudo constante das modificaçóes do mercado de consumo." 
Para movimentar a máquina governamental no que diz respeito ao consumo, o CDC, no artigo 105, previu um Sistema Nacional de Defesa do Consumidor, composto por órgãos federais, estaduais, do Distrito Federal e municipais, além de entidades privadas de defesa do consumidor.

No âmbito do SNDC, cabe à Secretaria Nacional do Consumidor (Senacon), ${ }^{9}$ por meio do Departamento de Proteção e Defesa do Consumidor (DPDC), a coordenação política do SNDC, o que envolve a elaboração, proposição, coordenação e execução da política nacional de proteção ao consumidor; o tratamento de consultas, denúncias ou sugestóes; a informação e conscientização; o incentivo à formação de entidades de defesa do consumidor, entre outras finalidades previstas no artigo 106 do CDC.

As nomeaçóes e designaçóes na Senacon são realizadas, na forma do Decreto n. 8.821/2016, pelo ministro chefe da Casa Civil, ou seja, são nomeaçóes que ficam sujeitas aos efeitos de instabilidades políticas e trocas de governo. O efeito disso é a possibilidade de constantes alteraçóes na estrutura da Senacon, podendo afetar o sistema como um todo (uma vez que cada nomeação pode implicar ajustes em prioridades e planos), dificultando a institucionalização do sistema. ${ }^{10}$

De acordo com Canaris, "o sistema deixa-se [...] definir como uma ordem axiológica ou teleológica de princípios gerais de Direito, na qual o elemento de adequação valorativa se dirige mais à característica de ordem teleológica e o da unidade interna à característica dos princípios gerais” (2002, p. 77). A organização do sistema (adequação valorativa) pode ser interpretada como a organização de normas e entidades que devem agir de acordo com um objetivo comum, que deve estar refletido na denominada "unidade interna". De um ponto de vista jurídico, é normal, portanto, que existam normas com o objetivo de construir um sistema coeso e bem orientado à unidade interna.

9 O texto original do CDC refere-se à Secretaria Nacional de Direito Econômico, contudo o Decreto 7.738 de 28 de maio de 2012 criou a Senacon, aumentando a estrutura e a autonomia do órgáo administrativo ligado à defesa do consumidor. A criação da Senacon é entendida como um claro indício de que a defesa do consumidor é um tema importante na agenda do Estado brasileiro.

${ }^{10}$ Como lembra Frey, "as disputas políticas e as relaçôes de força de poder sempre deixarão suas marcas nos programas e projetos desenvolvidos e implementados" (2000, p. 219). 
Com essa ambição, o Decreto n. 2.181 de 20 de março de 1997 dispôs sobre a organização do SNDC e especificou que os órgãos estaduais, do Distrito Federal e municipais de defesa do consumidor teriam praticamente as mesmas atribuiçôes da Senacon, mais a tarefa de elaborar políticas regionais de proteção ao consumidor, de dar atendimento aos consumidores, de julgar procedimentos administrativos no âmbito de sua competência, entre outras atribuiçóes previstas no artigo $4^{\circ}$ do referido decreto.

No que diz respeito às entidades civis de proteção ao consumidor, o Decreto 2.181 apenas atribuiu a elas as funções de "encaminhar denúncias aos órgãos públicos de proteção e defesa do consumidor, para as providências legais cabíveis; representar o consumidor em juízo" e "exercer outras atividades correlatas" (artigo 8º).

Além disso, o Decreto 2.181 preocupou-se em elencar práticas infrativas (artigos 12 a 17); especificar regras para as penalidades administrativas já previstas no CDC (artigos 18 a 28); estabelecer regras para a destinação das multas aplicadas (artigos 29 a 32); definir as regras do processo administrativo para aplicaçáo dessas penalidades (artigos 33 a 55); autorizar a Senacon a complementar o rol de cláusulas abusivas previstas no artigo 51 do CDC (artigo 56) e estabelecer como deve ser o Cadastro de Fornecedores (artigos 57 a 62).

A organização do SNDC, como se depreende da leitura dos dispositivos legais respectivos, náo buscou propriamente "organizar um sistema”, mas sim estabelecer regras para instituir processos administrativos e impor penalidades.

Com efeito, não são encontradas no Decreto 2.181 regras que estabeleçam a atuação conjunta dos órgãos que compóem o SNDC para o fim de elaborar políticas públicas, como de educação e informação a fornecedores e consumidores.

Essa formatação do SNDC faz com que os seus órgãos concentrem seus recursos e energias em procedimentos administrativos para fiscalização de fornecedores e resolução de conflitos no âmbito dos Procons, tratando de cuidar apenas da dimensão individual da cidadania ligada ao consumo. 
De fato, embora o SNDC tenha sido instituído em 1990 (com o CDC) e regulamentado em 1997 (com o Decreto 2.181), verifica-se que ainda existe um trabalho bastante extenso em andamento para articular e uniformizar as açôes de todas as 683 unidades de atendimento aos consumidores, distribuídas por 531 cidades brasileiras. ${ }^{11}$

Um exemplo disso foram as políticas públicas estabelecidas por meio de uma parceria celebrada entre a Senacon e a Unesco no ano de 2010 para integrar e uniformizar o SNDC. Nesse contexto, foram feitos investimentos para melhorar a integração das informaçôes dos Procons por meio do Sistema Nacional de Informaçóes de Defesa do Consumidor (Sindec). De acordo com relatório da Senacon, essas informações melhoraram a atuação dos órgãos regionais na solução de conflitos, na medida em que "as empresas que mais receberam reclamaçóes [...] foram convidadas a participar, de forma ativa e direta, na prevenção de problemas e na resolução de demandas registradas pelos consumidores nos Procons integrados" (BRASIL, 2016, p. 7). Outra frente de ação dessa política foi a matriz "educacional" que, basicamente, consistiu em aprimorar a atuação da Escola Nacional de Defesa do Consumidor (ENDC) e disseminar cursos especialmente para os Procons.

Embora se verifique a existência de políticas que tentem integrar os órgãos estatais que compóem o SNDC, a mesma tentativa de integração não ocorre em relação aos demais atores que desempenham um papel importante nas relaçóes de consumo, notadamente as entidades privadas de defesa do consumidor e os fornecedores.

Neste particular, deve-se ter em mente que a integração e articulação entre os organismos estatais e não estatais é fundamental para que o SNDC possa concretizar os princípios da Política Nacional das Relaçôes de Consumo previstos no

${ }^{11}$ Dados de 2016, extraídos do relatório produzido pela Senacon (BRASIL, 2016, p. 3). 
artigo $4^{\circ}$ do CDC. ${ }^{12} \mathrm{~A}$ atuação do Estado, igualmente fundamental para proteger o consumidor vulnerável, deve buscar a integração entre todos os atores envolvidos, de modo a evitar conflitos e, quando existentes, resolvê-los. ${ }^{13}$

As entidades civis (associaçóes e movimentos de defesa) desempenham, sem dúvida, um papel importante para a efetivação dos direitos dos consumidores. Como já frisado anteriormente, no entanto, o seu papel no atual contexto é bastante restrito, ficando limitado a encaminhar denúncias aos órgáos públicos e representar o consumidor em juízo nas hipóteses legais. A participação dessas entidades na formulação e efetivação das políticas públicas de consumo é um passo fundamental para a concretização da dimensão coletiva da cidadania ligada ao consumo, especialmente porque tais entidades expressamente fazem parte do SNDC.

Ademais, a maior participação dos fornecedores nos processos de discussão, elaboração e estabelecimento das políticas públicas poderia favorecer a integração do sistema. De fato, as chances de êxito de uma política pública de consumo são substancialmente maiores nas situaçóes em que se consegue lograr a convergência de interesses entre consumidores, Estado, entidades civis e fornecedores.

Essa integração pode ser aprimorada com audiências públicas para elaboração de políticas de consumo e com o desenvolvimento de programas que envolvam um papel ativo de fornecedores e entidades civis representativas de consumidores. Alguns exemplos nessa linha seriam possíveis programas para solução de conflitos e tratamento da situação de consumidores endividados; o aprimoramento de me-

\footnotetext{
${ }^{12}$ Verbicaro lembra a importância do artigo $4^{\circ}$ do $\mathrm{CDC}$, cujo alcance não se limita "a uma função meramente programática, pois objetiva integrar, através de uma rede de diálogos políticos, o próprio Estado, a sociedade de consumidores e os fornecedores, ou seja, tem-se a concretizaçáo do ideal de solidariedade emancipatória por meio de um debate permanente e racional entre os partícipes das relações de consumo, com vistas a aperfeiçoar sua normatização jurídica e melhor balizar a atuação administrativa e judicial de todos os órgáos integrantes do sistema nacional das relaçóes de consumo" (VERBICARO, 2017).

${ }^{13}$ Como lembra Costa, "[...] pouco a pouco, os representantes da sociedade civil e os políticos perceberam que o mercado náo era suficiente para regulamentar o consumo, daí haver a necessidade de intervenção pública para equilibrar as relaçóes, em que o consumidor era considerado hipossuficiente em relação ao fornecedor [...] As políticas públicas das relaçôes de consumo passaram a ser uma atividade do Estado, em colaboração com associaçóes e movimentos de defesa do consumidor, para definir a proteção deste e para estabelecer regras para solucionar os conflitos de interesse entre as partes, começando a exigir atençẫo da agenda pública” (2016, p. 199).
} 
canismos de autorregulação já existentes (como ocorre em relação à publicidade); a discussão de novos mecanismos de autorregulação (por exemplo, em relação às boas práticas atinentes à coleta, tratamento e utilização de dados pessoais); a instituição de acordos setoriais para questóes que envolvem boas práticas em relação à sustentabilidade e meio ambiente, entre tantas outras possíveis.

Também seria fundamental para a articulação do SNDC na forma ora proposta que a convenção coletiva de consumo, prevista no artigo 107 do CDC, ${ }^{14}$ começasse a ser utilizada como um instrumento efetivo de regulação nas relaçóes entre consumidores e fornecedores, evitando conflitos e contribuindo para a harmonização do mercado.

Além disso, seria desejável que os órgãos regionais de defesa dos consumidores (Procons) também adotassem políticas seguindo os parâmetros ora propostos. As políticas em âmbito regional podem oferecer melhores resultados à população local, especialmente em um país de dimensóes continentais e de heterogeneidade cultural como é o Brasil.

A estruturação e efetividade do SNDC com vistas a ideias diretrizes que possam efetivar todas as dimensóes da cidadania ligada ao consumo permitirá a instalação de políticas públicas que sejam capazes de alcançar esses resultados. $\mathrm{Na}$ próxima seção objetiva-se explorar o tema das políticas públicas de consumo e de sua efetividade no atual contexto da defesa do consumidor no Brasil.

\footnotetext{
14 "Art. 107. As entidades civis de consumidores e as associações de fornecedores ou sindicatos de categoria econômica podem regular, por convençáo escrita, relações de consumo que tenham por objeto estabelecer condiçōes relativas ao preço, à qualidade, à quantidade, à garantia e características de produtos e serviços, bem como à reclamação e composição do conflito de consumo. $\S 1^{\circ} \mathrm{A}$ convenção tornar-se-á obrigatória a partir do registro do instrumento no cartório de títulos e documentos. $\S 2^{\circ}$ A convenção somente obrigará os filiados às entidades signatárias. $\$ 3^{\circ}$ Não se exime de cumprir a convenção o fornecedor que se desligar da entidade em data posterior ao registro do instrumento."
} 


\section{POLÍTICAS PÚBLICAS DE CONSUMO NO BRASIL}

Uma política pública pode ser definida como um programa governamental que é consequência de um conjunto de processos para alcançar objetivos previamente e politicamente determinados, selecionando prioridades, reservando os recursos necessários e estabelecendo metas para atingir os resultados esperados. ${ }^{15}$

A articulação entre diversas entidades é essencial para o sucesso de uma política pública. Os órgãos governamentais, de acordo com Dye, darão à política pública os atributos da legitimidade (impondo obrigaçóes legais aos envolvidos), universalidade (são aplicáveis e oponíveis a todas as pessoas) e coerção (possibilidade de imposição de penalidades a quem não observa a norma) (DYE, 2006, p. 101).

Além dos órgãos governamentais, também é possível que uma política pública conte com a participaçấo de entidades não governamentais ligadas ao tema e às açôes previstas. No tema do consumo, como já explorado na seção 2 , a atuação de entidades privadas de defesa do consumidor e de fornecedores poderia ser agregada à atuação do governo.

No que respeita aos objetivos principais, as políticas públicas, como lembra Smanio, devem "ter o norte da cidadania em todas as suas dimensóes, integrando os diversos aspectos sociais, políticos e econômicos, bem como atendendo às necessidades de inclusão social, pois esta é a determinação constitucional de 1988" (SMANIO, 2008, p. 343). Nos temas referentes ao consumo o norte da política pública deve ser a ideia de cidadania desenvolvida na seção 1 desse trabalho.

Uma política pública bem-sucedida é importante porque pode alterar o comportamento das pessoas, instituindo novos parâmetros de comportamento. Nyborg (2003) elabora um estudo neste sentido, demonstrando que certas políticas

\footnotetext{
${ }^{15}$ Na definição de Maria Paula Dallari Bucci, a política pública é “o programa de ação governamental que resulta de um processo ou conjunto de processos juridicamente regulados - processo eleitoral, processo de planejamento, processo de governo, processo orçamentário, processo legislativo, processo administrativo, processo judicial - visando coordenar os meios à disposição do Estado e as atividades privadas, para a realização de objetivos socialmente relevantes e politicamente determinados. Como tipo ideal, a política pública deve visar a realização de objetivos definidos, expressando a seleção de prioridades, a reserva de meios necessários à sua consecução e o intervalo de tempo em que se espera o atingimento dos resultados" (2006, p. 39).
} 
públicas podem influenciar o comportamento das pessoas e as normas sociais. Segundo a autora, o Estado pode instituir impostos, conceder incentivos financeiros, fazer publicidade ou criar regras para certas atividades, tendo como consequência mudanças de comportamento social.

O sucesso de uma política pública, contudo, também depende de um processo adequado de definição e estabelecimento. Para alcançar esse êxito é importante que sejam observadas todas as etapas desse processo. Duarte explica essas etapas no ciclo das políticas públicas, que envolve a sua correta formulação (definição, pelo poder Executivo, da política, levando em conta os recursos disponíveis, meios técnicos, científicos, jurídicos e financeiros necessários); execução (ou instituição); avaliação (verificação dos impactos concretos, aferindo se as metas, meio e forma de execuçáo foram realizados de acordo com os ditames constitucionais e dentro do previsto na política); fiscalizaçáo e controle (pela sociedade civil, Conselhos Gestores ou outros mecanismos de pressão) (DUARTE, 2013, p. 25).

Em matéria de consumo, o Plano Nacional de Consumo e Cidadania (Plandec), instituído pelo Decreto n. 7.963 de 15 de março de 2013, apontou para a inclusão do tema na agenda do Estado brasileiro e para o entendimento de que consumo e cidadania são conceitos interligados. De acordo com o artigo $1^{\circ}$ da referida norma, o Plandec teve a intenção de "promover a proteção e defesa do consumidor em todo o território nacional, por meio da integração e articulação de políticas, programas e açóes”.

Com o objetivo de analisar o referido plano no campo das políticas públicas, será utilizado o Quadro de Referência proposto por Bucci (2015), identificando-se a seguir os principais elementos do referido plano, constantes do Decreto n. 7.963:

1. Nome oficial do programa de ação: Plano Nacional de Consumo e Cidadania.

2. Gestão governamental: programa criado pelo poder Executivo, por meio de Decreto Governamental.

3. Base Normativa: Decreto n. 7.963, de 15 de março de 2013. 
4. Desenho jurídico-institucional: o Plandec, no artigo $9^{\circ}$ do Decreto 7.963, cria a Câmara Nacional das Relaçóes de Consumo, com duas instâncias principais: o Conselho de Ministros (órgáo de coordenaçáo) e o Observatório Nacional das Relaçóes de Consumo. Demais agentes governamentais e não governamentais também atuarão conforme atribuiçóes definidas na norma (itens v e vi a seguir).

5. Agentes Governamentais: Conselho de Ministros do Plandec (com a função de orientar a formulação, a instituição, o monitoramento e a avaliação do Plano); Observatório Nacional das Relaçóes de Consumo (coma missão de promover estudos e formular propostas, acompanhar a execução das políticas, programas e açóes); Ministério da Justiça (para apoio administrativo ao funcionamento da Câmara Nacional das Relações de Consumo; coordenação, gerenciamento e ampliação do Sindec); Estados e municípios (devem interiorizar e ampliar o atendimento ao consumidor); Procons (defesa dos consumidores).

6. Agentes Não Governamentais: Entidades privadas (poderão firmar convênios, acordos de cooperação ou instrumentos congêneres).

7. Mecanismos Jurídicos de Articulação: não estão previstas no Decreto 7.963 .

8. Escala e público-alvo: programa de abrangência nacional, objetivando o aprimoramento das relaçóes de consumo em todo o país.

9. Dimensão econômico-financeira do programa: o Plandec será custeado por dotações orçamentárias da União; recursos oriundos dos órgãos participantes do Plandec; outras fontes de recursos destinadas por Estados, DF e municípios (artigo 14 do Decreto 7.963/2013).

10. Estratégia de instalação: a única ação concreta prevista no Decreto que institui o Plandec era a elaboração no prazo de 30 dias de uma lista de produtos essenciais, para regulamentar o artigo 18 do CDC. No mais, o programa estabelece que haverá utilização de dados e informaçóes do Sindec para definir políticas e açóes do Plandec (artigo $8^{\circ}$ ). Entre os eixos, objetivos e diretrizes do programa (artigos $2^{\circ}, 3^{\circ}$ e $4^{\circ}$ ) podem ser encontrados os seus focos de instituição e atuação, quais sejam: 
educação para o consumo; melhoria nos serviços públicos; acesso do consumidor à Justiça; fortalecimento da participação social na defesa dos consumidores; proteção de dados pessoais; promoção de acesso a padróes de produção e consumo sustentáveis; prevenção e solução de conflitos e reforço nas penalidades administrativas aplicadas aos fornecedores.

11. Funcionamento efetivo do programa: em 2013, o Decreto 7.986 retirou o prazo de 30 dias originalmente previsto para formulação da lista de produtos essenciais, visando à regulamentação do artigo 18 do CDC. Em 2016 a portaria n. 7 da Senacon disciplinou a aplicação de sançôes administrativas no âmbito daquele órgão. Em 2017 o Decreto 7.963 foi alterado pelo Decreto 8.953 de 10 de janeiro de 2017 para incluir no Plandec questôes referentes à acessibilidade na utilização de produtos e serviços. No ano de 2013 a Senacon celebrou diversos convênios com Procons no âmbito do Plandec com o objetivo de criar novos postos para atendimento ao consumidor (Convênios Siconv 792558/2013 com Amazonas; 792316/2013 com Ceará; 793535/2013 com Mato Grosso; 791894/2013 com Maranhão; 793536/2013 com Mato Grosso do Sul; 792258/2013 com Pernambuco; 793534/2013 com Rio Grande do Norte e 792550/2013 com Tocantins). No ano de 2014 foram firmados convênios a respeito de programas de educaçáo financeira a consumidores com o Idec (Convênio Siconv n. 813319/2014) e com a Adecon do Estado de Pernambuco (Convênio Siconv n. 813413/2014).

12. Aspectos críticos do desenho jurídico-institucional: o Plandec possui um robusto arcabouço normativo, constituído basicamente de Decretos do poder Executivo, no entanto, no que tange à efetividade do programa, há poucos indícios de açôes concretas, possivelmente em virtude da maior necessidade de articulação entre os entes envolvidos.

A primeira observação a se fazer é que a norma instituidora do programa tem objetivos que denotam as três acepçóes de cidadania mencionadas na seçấo 2: a dimensão do consumidor de serviços públicos é vislumbrada na diretriz de adequada e eficaz prestação de serviços públicos (artigo 2º, II); a concepção individual do consumidor cidadáo está presente, por exemplo, nas diretrizes de acesso do 
consumidor à Justiça (artigo 2o, III) e proteção de dados pessoais (artigo $2^{\circ}$, VII), assim como no eixo de prevenção e solução de conflitos (artigo 4º I); e a concepção coletiva do consumidor cidadão está materializada, entre outras, nas diretrizes de educação para o consumo (artigo $2^{\circ}, \mathrm{I}$ ), de fortalecimento da participação social na defesa dos consumidores (artigo 2, V) e no objetivo de promoção de acesso a padrôes de produção e consumo sustentáveis $\left(\operatorname{artigo~} 3^{\circ}, \mathrm{V}\right)$.

Embora a norma tenha uma orientação adequada à efetivação da cidadania ligada ao consumo, ela não deixa claro, no entanto, quais são os meios disponíveis para que o SNDC concretize tal orientação. Analisando as políticas públicas realizadas no âmbito da Senacon após o início do Plandec verifica-se que a efetiva ação em relação ao tema é tímida se comparada aos objetivos traçados.

De fato, logo no ano de 2013, como resultado da parceria com a Unesco, a Senacon lançou o portal "consumidor.gov.br". Essa ferramenta objetiva ser um dos meios para ampliar o atendimento a consumidores que estão em locais em que não há atuação administrativa do SNDC. Por meio desse portal, basicamente, consumidores podem registrar reclamações em relação a fornecedores (cuja adesão é voluntária), que deverão envidar esforços para resolvê-las rapidamente. De acordo com a Senacon, "a ferramenta [...] fornece ao Estado informaçóes essenciais para a elaboração e a implementação de políticas públicas de defesa dos consumidores, assim como incentiva a competitividade no mercado para melhora da qualidade da oferta e do atendimento ao consumidor" (BRASIL, 2016, p. 19). Claramente, essa ferramenta trabalha no eixo da prevenção e redução de conflitos (artigo $4^{\circ}$, I do Decreto 7963). Afora isso, a Senacon produziu cartilhas e estudos referentes a diversos temas, além de iniciar um debate sobre o tema da proteção de dados pessoais (assuntos que também são objeto do Plandec) e firmar os convênios para programas de educação financeira dos consumidores (conforme item "xi” mencionado anteriormente).

Como se vê, apesar das açóes concretizadas até o momento, ainda há um caminho longo a ser percorrido para que se atinjam os objetivos e as diretrizes da política pública estabelecida. Alguns elementos contribuem para isso. 
$\mathrm{O}$ primeiro deles refere-se à falta de clareza a respeito dos instrumentos de articulação das centenas de órgãos que constituem o SNDC. Com efeito, cada Procon, estadual ou municipal, age com autonomia, sem vinculação hierárquica à Senacon. Embora isso seja positivo do ponto de vista da possibilidade de regionalização das políticas públicas, a total autonomia somada ao grande número de órgãos não assegura que tais órgãos irão seguir diretrizes comuns, o que afeta a unidade do sistema. Tanto é assim que a Senacon, como já demonstrado anteriormente, vem investindo uma parte importante do seu tempo e dos seus recursos em projetos de formação técnica dos Procons, o que seria uma ferramenta para tentar atribuir a unidade ao SNDC.

Um outro fator que não contribui para a concretização das políticas públicas de consumo diz respeito ao problema da institucionalização. Como já mencionado na seção 3, os principais cargos da Senacon são ocupados por pessoas nomeadas pelo poder Executivo, o que significa que mudanças de governo em função do calendário eleitoral ou de eventos políticos podem impactar a continuidade das políticas iniciadas em gestôes anteriores. ${ }^{16}$

Por fim, a fata de interação entre os órgãos estatais do SNDC, de um lado, e as entidades privadas de defesa do consumidor e os fornecedores, de outro, além de prejudicar a efetividade do SNDC (conforme já mencionado na seção 4), inviabiliza a concepção e implementação de Políticas Púbicas que envolvam a participação de todos os entes do mercado. Esse fator restringe as Políticas Públicas da Senacon àquelas já mencionadas acima (treinamentos, elaboraçáo de material educativo) que envolvem basicamente a própria Senacon e os Procons. Políticas buscando o efetivo engajamento dos fornecedores e uma mudança de comportamento global no mercado de consumo precisam ser concebidas conjuntamente, pois isso aumenta do compromisso dos atores envolvidos. O portal "consumidor. gov.br", mencionado acima, embora ainda esteja em fase embrionária, é um sinal de que é possível buscar ferramentas de atuação conjunta tendentes a harmonizar as relaçóes de consumo.

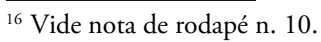




\section{CONCLUSÃO}

Em decorrência de todo o anteriormente exposto, pode-se afirmar que cidadania e consumo são conceitos que estão ligadas em pelo menos três dimensôes: a do consumidor de serviços públicos, a do viés individual do cidadão consumidor e a do viés coletivo do consumo.

Também é possível concluir que o SNDC ainda está muito voltado para superar dificuldades de integração e articulação do sistema no âmbito dos órgãos estatais, sendo de extrema importância o desenvolvimento de açóes que busquem novas e efetivas formas de atuação, envolvendo maior participação de entidades civis e fornecedores, tanto no âmbito nacional quanto regionalmente.

Não obstante, e apesar da estrutura jurídica atual do SNDC (que prioriza a fiscalização, aplicação de penalidades e o procedimento administrativo), há um movimento para que as políticas públicas de consumo ocorram, destacando-se que o Plandec revela uma ideia diretriz na linha da cidadania ligada ao consumo.

Sendo assim, o próximo passo para a efetiva concretização dos princípios estabelecidos no artigo $4^{\circ}$ do CDC, especialmente a harmonização entre consumidores e fornecedores, pode ser o desenvolvimento de políticas públicas de consumo que integrem também as entidades civis e os fornecedores, inclusive em âmbito regional, com uma atuação dos Procons menos voltada às multas e fiscalizações e mais direcionada à criação e estabelecimento de políticas voltadas aos objetivos e diretrizes que concretizem o viés cidadão do consumo, em todas as suas dimensôes.

\section{REFERÊNCIAS}

BRASIL. Secretaria Nacional do Consumidor. Departamento de Proteçáo e Defesa do Consumidor. Desenvolvimento de Mecanismos de Gestäo da Informação e do Conhecimento para as Politicas Públicas de Defesa do Consumidor: Balanço Social do Projeto 91BRZ5005. Brasília: Ministério da Justiça, 2016. Disponível em: <http://portal.defesadoconsumidor. gov.br/images/manuais/Balanco_geral_GFKA.pdf>. Acesso em: 2 maio 2017.

BUCCI, Maria Paula Dallari. O conceito de políticas públicas em Direito. In: BUCCI, Maria Paula Dallari (Org.). Políticas públicas: reflexôes sobre o conceito jurídico. São Paulo: Ed. Saraiva, 2006. 
BUCCI, Maria Paula Dallari. Quadro de referência de uma política pública: primeiras linhas de uma visão jurídico-institucional. In: SMANIO, Gianpaolo Poggio; BERTOLIN, Patricia Tuma Martins; BRASIL, Patricia Cristina (Org.). O Direito na Fronteira das politicas públicas. São Paulo, Paz \& Letras, 2015.

CANARIS, Claus-Wilhelm. Pensamento sistemático e conceito de sistema na Ciência do Direito. 3. ed. Lisboa: Fundação Calouste Gulbenkian, 2002.

COSTA, Nelson Nery. Politica de consumo: movimento social de defesa do consumidor no Brasil. Belo Horizonte: Del Rey, 2016.

DUARTE, Clarice Seixas. O ciclo das políticas públicas. In: SMANIO, Gianpaolo Poggio; BERTOLIN, Patrícia Tuma Martins; BRASIL, Patricia Cristina (Org.). O Direito e as políticas públicas no Brasil. São Paulo: Atlas, 2013.

DYE, Thomas. Mapeamento dos modelos de análise das políticas públicas. In: HEIDEMANN, Francisco G.; SALM, José Francisco (Org.). Políticas públicas e desenvolvimento. Bases epistemológicas e modelos de análise Brasília: Editora UNB, 2006.

FREY, Klaus. Políticas públicas: um debate conceitual e reflexóes referentes à prática da análise de políticas públicas no Brasil. Planejamento e Políticas Públicas, [s.l.], v. 21, p.211259, jun. 2000. Disponível em: <http://www.ufpa.br/epdir/images/docs/paper21.pdf>. Acesso em: 31 maio 2017.

MAURER, Angela Maria et al. Yes, we also can! O desenvolvimento de iniciativas de consumo colaborativo no Brasil. Base, [s.l.]: Unisinos - Universidade do Vale do Rio Dos Sinos, v. 12, n. 1, p. 68-80, 13 abr. 2015. DOI: http://dx.doi.org/10.4013/base.2015.121.06.

NYBORG, Karine. The impact of Public Policy on Social and Moral Norms: Some Examples. Journal Of Consumer Policy, [s. 1.], p. 259-277, 2003. Trimestral.

PELLEGRINI, Guilherme Martins. A responsabilidade do Estado-Fornecedor com base no Código de Defesa do Consumidor. Revista de Direito do Consumidor, São Paulo, v. 105, p. 295-318, maio/jun. 2016.

PINA, Susana de; ARRIBAS, Victoria. O cidadão consumidor: o nascimento de uma nova categoria. In: LEITÃO, Debora Krischke; LIMA, Diana Nogueira de Oliveira; MACHADO, Rosana Pinheiro. Antropologia e consumo: diálogos entre Brasil e Argentina. Porto Alegre: Age, 2006. p. 81-98.

PROTHERO, Andrea et al. Sustainable Consumption: Opportunities for Consumer Research and Public Policy. Journal Of Public Policy \& Marketing, [s. 1.], v. 30, n. 1, p.31-38, 2011. Semestral. 
SMANIO, Gianpaolo Poggio. A conceituação da cidadania brasileira e a Constituição Federal de 1988. In: MORAES, Alexandre de (Org.). Os 20 anos da Constituição da República Federativa do Brasil. São Paulo: Atlas 2008.

. As dimensões da cidadania. In: Novos Direitos e Proteção da Cidadania-Revista Jurídica da Escola Superior do Ministério Público, ano 2, jan./jun. 2009.

TASCHNER, Gisela. Cultura do consumo, cidadania e movimentos sociais. Csu, [s.1.]; Unisinos - Universidade do Vale do Rio dos Sinos, v. 46, n. 1, p. 47-52, 10 maio 2010. DOI: http://dx.doi.org/10.4013/csu.2010.46.1.06.

VERBICARO, Dennis. A construção de um novo modelo de cidadania participativa do consumidor a partir da política nacional das relaçóes de consumo. Revista de Direito do Consumidor, São Paulo, v. 110, p. 311-339, mar. 2017. Bimestral.

VOLPI, Alexandre. A história do consumo no Brasil: do mercantilismo à era do foco no cliente. Rio de Janeiro: Elsevier, 2007. 